\title{
Management of labial adhesion in a developing country-an observational study
}

Saurabh Srivastava, Anand Pandey* ${ }^{*}$, Piyush Kumar, Survesh K. Gupta, Sudhir Singh and Jiledar Rawat

\begin{abstract}
Background: Labial adhesion is the fusion of the labia minora or majora. The literature reports conservative management. However, the situation may be different in our setup, where management differs due to prevailing circumstances. The present study was conducted to evaluate labial adhesion presentation, management, and outcome in our center.
\end{abstract}

Methods: It was a retrospective observational study from January 2015 to January 2020. The patients were evaluated for age at presentation, presenting symptoms, type of adhesions, treatment, recurrence, and follow-up. The treatment included the manual release of labial adhesion and Mupirocin ointment application for 15 days. They were advised to attend the outpatient department after 1 month for evaluation and later on in case of any problem.

Results: The total number of patients was 150, of which 104 (69.33\%) were from rural backgrounds. The complaint was of the absent vaginal opening in all patients. Seventeen (11.33\%) were advised ultrasonography of the abdomen elsewhere to look for the presence of internal genital organs. The local examination revealed poor hygiene in 65 (43.33\%) patients. The patient with thick adhesions has minor erythema after the release of adhesions. Ten (6.66\%) patients had a recurrence managed by repeat release with no recurrence.

Conclusion: Despite being a benign entity, labial adhesion may be a cause of severe concern. Manual separation and antibiotic ointment may be a viable first option in its management with minimal recurrence. Maintenance of local hygiene may be needed to prevent a recurrence. The overall outcome is excellent.

Keywords: Labial adhesion, Labial synechia, Management, Pediatric gynecology

\section{Background}

Labial adhesion (LA) is the fusion of the labia minora or majora, and it is mostly located near the clitoris. It is also known as labial synechia or labial agglutination [1]. It occurs most commonly between 3 months and 3 years of age. The estimated prevalence of labial adhesions is $0.6-5 \%$, with a peak incidence between 13 and 23 months $[2,3]$.
It is a benign pediatric gynecological entity, and most patients are asymptomatic. However, there may be dysuria or urinary tract infection (UTI) complaints in some patients [4]. The literature reports conservative management with no intervention for the majority of patients. However, the situation may be different in our setup, where management differs due to prevailing circumstances. The present study was conducted to evaluate LA's presentation, management, and outcome in our center.

\footnotetext{
*Correspondence: dranand27@rediffmail.com

Department of Pediatric Surgery, King George's Medical University,

Lucknow, UP 226003, India
} 


\section{Methods}

It was a retrospective observational study of patients of labial adhesions conducted in the Department of Pediatric Surgery of a university hospital from January 2015 to January 2020. We followed Strengthening the Reporting of Observational Studies in Epidemiology (STROBE) guidelines endorsed by the EQUATOR Network for conducting this study.

The patients were evaluated for age at presentation, presenting symptoms, type of adhesions, treatment, recurrence, and follow-up (Fig. 1). The inclusion criteria included all patients with a confirmed diagnosis of LA. The patients were also evaluated for medical advice taken elsewhere and any investigation done prior to visiting us. The patients were advised urine routine and microscopy examination to rule out UTI.

After ruling out UTI, manual release of LA was performed (Fig. 2). After that, the attendants were advised to apply Mupirocin ointment locally thrice a day for 15 days and maintain local hygiene. They were advised to attend the outpatient department (OPD) after 1 month for evaluation. After that, they were advised to come to OPD in case of any problem, such as recurrence.

\section{Results}

During the study period of 5 years, the total number of patients was 150 . The prevalence of LA was $1.7 \%$ of OPD attendance. The mean and median age of the patients was $22.32 \pm 29.45$ and 12 months (range 1-204 months). One hundred and twenty-one $(80.6 \%)$ patients presented in the first 2 years of life. One hundred and four (69.33\%) were from a rural background, and the remaining 46 (30.66\%) were of urban background.

The clinical complaint in all the patients was absent vaginal opening, which was noted during massaging,



Fig. 1 A patient of labial adhesion before release

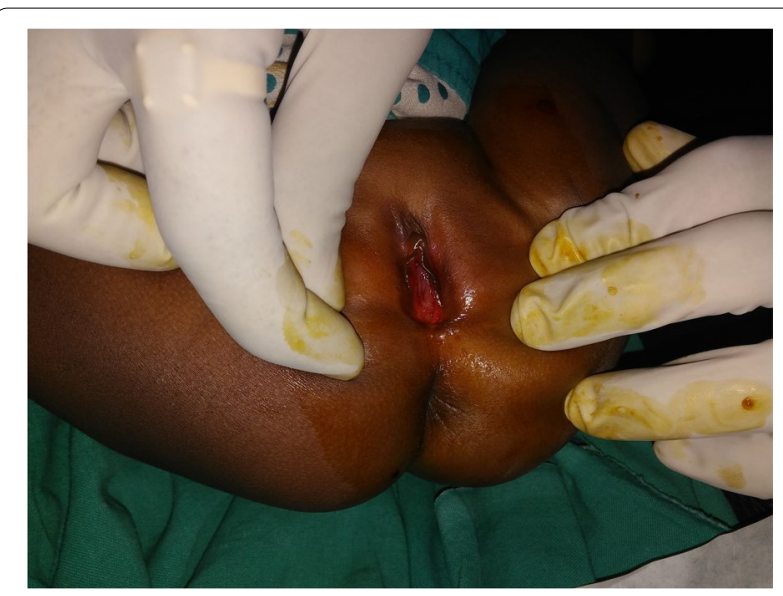

Fig. 2 After release, the vaginal opening is visible in the vestibule

bathing, or changing a diaper. The attendants of 109 (72.6\%) patients had taken advice from the local general practitioner, pediatricians, or gynecologist. All of them were referred to our center with the same clinical diagnosis of the absent vaginal opening. Seventeen (11.33\%) were advised ultrasonography (USG) of the abdomen to look for uterus and ovaries. All the attendants were quite apprehensive while stating the complaint.

The local examination revealed poor hygiene in 65 (43.33\%) patients, which was suggested by the presence of inadequately cleaned parts and the presence of smegma. Urine routine examination revealed more than five pus cells/HPF in 7 (4.66\%) patients. The culture examination in these patients revealed the presence of UTI due to Escherichia coli. It was treated with an oral antibiotic course successfully. Intraoperatively, thick adhesions were present in 21 (14\%) patients. The remaining 129 (86\%) patients had thin adhesions. The patient with thick adhesions has minor erythema after the release of adhesions, but there was no bleeding.

In the follow-up, $10(6.66 \%)$ patients had a recurrence after a mean duration of 7.58 months (range 6-9 months). They were managed by repeat release. All of them had poor local hygiene. There was no recurrence after it.

\section{Discussion}

The prevalence of LA in the current study was $1.7 \%$, aligning with the existing literature $[1,5]$. Since most of the Indian population lives in villages, it was reflected in the study too, where close to $70 \%$ of patients belonged to the rural background. The patients whose presentation was delayed may be due to this reason. The health facilities are limited in the villages [6, 7]. The transport facilities are also inadequate. It leads to delayed diagnosis and 
travel problems compound the situation, thus delaying the evaluation and management at an expert center.

The attendants had a common complaint of the absent vaginal opening. The attendants were very apprehensive of the possibility of vaginal absence. The possibility of an absent vagina may lead to a feeling of distortions of body image and psychological distress. It may lead to anxiety and depression [8]. The pediatric surgical facilities are limited to less than $50 \%$ of districts of India [9]. Besides, the training centers are limited [10]; hence, many clinicians do not have exposure to pediatric surgical clinical situations. It can be gauged that some patients underwent unnecessary USG abdomen to look for internal genitalia based on suspicion of vaginal atresia. The other clinical problems may be UTI, abnormal urinary stream, recurrent vulvar or vaginal infections, and post-void dripping. Rarely, hydronephrosis secondary to urinary retention has also been reported $[2,4,11]$.

LA is not a congenital anomaly, and its exact cause is not clear [12]. It has been suggested that chronic inflammation from infection, poor perineal hygiene, or trauma can erode the epithelium of the labia minora. In association with minimal estrogen in prepubertal females, it may facilitate adhesion of the labia minora [11, 13]. However, in one study, serum estradiol levels of 59 prepubertal females with LA and 60 prepubertal females showed no statistically significant difference in the estrogen levels [1]. In the current series, poor perineal hygiene was noted in $65(43.33 \%)$ patients. It is not clear whether UTI was secondary to LA or its precursor.

Our management strategy differs from what is mentioned in the literature. Most of the literature is from the USA or European countries [2, 3, 5, 12, 14]. The preferred choice of management is either observation or estrogen/ steroid cream and follow-up in the OPD. As mentioned earlier about factors, such as monetary or transportation issues, the attendants do not wish to visit the OPD unless deemed extremely necessary. Hence, the options of application of an estrogen or steroid cream with follow-up become a tad difficult. Besides, it is not necessary that the attendants will come on the next scheduled visit. They may keep on applying the cream till then. There are side effects of estrogen cream mentioned, such as hyperpigmentation of the labia and breast development. Besides, there can be a possibility of vaginal bleeding and precocious puberty $[2,5]$. Moreover, the success rate of applying estrogen or betamethasone cream is close to $70 \%$ and $80 \%$, respectively [2], although some recent reports have better responses [13].

Manual separation is an office procedure. When explained, all of the attendants chose manual separation. The idea of observation was rejected as they wanted immediate treatment due to the apprehension, as discussed earlier. The majority of patients fared well with the application of an antibiotic ointment after manual release, and we did not need estrogen cream after manual release as recommended [13]. It has been found to be more effective than estrogen cream alone [15].

The incidence of recurrence has wide variations from 7 to $55 \%$ [13]. The treatment modality in these series is not clear. Our recurrence incidence was $6.6 \%$, which is less than the minimum range reported. It is probably due to the procedure of manual release. The patients who had recurrence did not follow the advice properly, and the perineal hygiene was not good. It may be the reason for the recurrence. However, after re-release, no further recurrence was noted. An uncommon cause of recurrence, such as congenital adrenal hyperplasia, may be looked at if there are multiple recurrences [16]. The limitation of this study can be its retrospective nature; however, we believe that the detailed analysis of data may compensate for this deficit.

\section{Conclusion}

Despite being a benign entity, LA may be a cause of severe concern. Manual separation and use of antibiotic ointment may be a viable first option in its management with minimal recurrence. Maintenance of local hygiene may be needed to prevent a recurrence. The overall outcome is excellent.

\section{Acknowledgements \\ None.}

Authors' contributions

SaS and AP conceptualized the idea. PK, SaS, SuS, and AP performed the literature review and collected the data. AP, SaS, and PK wrote the first draft of the manuscript. JR reviewed the manuscript. AP and JR prepared the final draft. The final version was read and approved by all authors.

\section{Funding}

None.

Availability of data and materials

Not applicable.

\section{Declarations}

\section{Ethics approval and consent to participate}

The data of the present study were collected in the course of common clinical practice, and accordingly, the signed informed consent was obtained from each patient for any surgical and clinical procedure. The study protocol was in accordance with the ethical standards of the institutional research committee and the 1964 Helsinki Declaration and its later amendments. Because it was a retrospective study, formal consent for this study was not required, and no approval of the Institutional Research Committee, King George's Medical University, U.P. (registration no. ECR/262/Inst/UP/2013/RR-19) was needed.

\section{Consent for publication}

Obtained from parents of the patient. It is available if requested.

\section{Competing interests}

None. 
Received: 29 October 2021 Accepted: 27 November 2021

Published online: 06 December 2021

\section{References}

1. Gonzalez D, Anand S, Mendez MD (2021) Labial adhesions. In: StatPearls. StatPearls Publishing, Treasure Island

2. Eroğlu E, Yip M, Oktar T, Kayiran SM, Mocan H (2011) How should we treat prepubertal labial adhesions? Retrospective comparison of topical treatments: estrogen only, betamethasone only, and combination estrogen and betamethasone. J Pediatr Adolesc Gynecol 24:389-391. https://doi. org/10.1016/j.jpag.2011.07.015

3. Granada C, Sokkary N, Sangi-Haghpeykar H, Dietrich JE (2015) Labial adhesions and outcomes of office management. J Pediatr Adolesc Gynecol 28:109-113. https://doi.org/10.1016/j.jpag.2014.06.004

4. Melek E, Kılıçbay F, Sarıkaş NG, Bayazıt AK (2016) Labial adhesion and urinary tract problems: the importance of genital examination. J Pediatr Urol 12(111):e1-e5. https://doi.org/10.1016/j.jpurol.2015.10.002

5. Myers JB, Sorensen CM, Wisner BP, Furness PD 3rd, Passamaneck M, Koyle MA (2006) Betamethasone cream for the treatment of prepubertal labial adhesions. J Pediatr Adolesc Gynecol 19:407-411. https://doi.org/10. 1016/j.jpag.2006.09.005

6. Gangopadhyay AN (2020) Pediatric surgery in rural India: past, present, and future. J Indian Assoc Pediatr Surg 25:193-194. https://doi.org/10. 4103/jiaps.JIAPS_113_20

7. Panagariya A (2014) The challenges and innovative solutions to rural health dilemma. Ann Neurosci 21:125-127. https://doi.org/10.5214/ans. 0972.7531 .21040

8. Gupta NP, Ansari MS (2002) Mayer-Rokitansky-Kuster-Hauser (MRKH) syndrome- a review. Indian J Urol 18:11-16
9. Shah $\mathrm{R}$ (2015) The past, the present, and the future of pediatric surgery in India. J Indian Assoc Pediatr Surg 20:2-7. https://doi.org/10.4103/09719261.145436

10. Gupta DK (2015) Pediatric surgery in India: time now for review. J Indian Assoc Pediatr Surg 20:57-59. https://doi.org/10.4103/0971-9261.151543

11. Goel P, Gupta CR, Manchanda V, Jain V (2014) Novel presentation of labial synechiae: two urinary streams. J Obstet Gynaecol India 64:68-69. https:// doi.org/10.1007/s13224-012-0272-3

12. Soyer $T$ (2007) Topical estrogen therapy in labial adhesions in children: therapeutic or prophylactic? J Pediatr Adolesc Gynecol 20:241-244. https://doi.org/10.1016/j.jpag.2006.09.015

13. Bacon JL, Romano ME, Quint EH (2015) Clinical recommendation: labial adhesions. J Pediatr Adolesc Gynecol 28:405-409. https://doi.org/10. 1016/j.jpag.2015.04.010

14. Muram D (1999) Treatment of prepubertal girls with labial adhesions. J Pediatr Adolesc Gynecol 12:67-70. https://doi.org/10.1016/s10833188(00)86629-2

15. Bussen S, Eckert A, Schmidt U, Sütterlin M (2016) Comparison of conservative and surgical therapy concepts for synechia of the labia in pre-pubertal girls. Geburtshilfe Frauenheilkd 76:390-395. https://doi.org/ 10.1055/s-0035-1558101

16. Janus D, Wojcik M, Malunowicz E, Starzyk JB (2012) A case of recurrent labial adhesions in a 15-month-old child with asymptomatic nonclassic congenital adrenal hyperplasia due to 21-hydroxylase deficiency. J Pediatr Endocrinol Metab 25:1017-1021. https://doi.org/10.1515/ jpem-2012-0190

\section{Publisher's Note}

Springer Nature remains neutral with regard to jurisdictional claims in published maps and institutional affiliations.

\section{Submit your manuscript to a SpringerOpen ${ }^{\circ}$ journal and benefit from:}

- Convenient online submission

- Rigorous peer review

- Open access: articles freely available online

- High visibility within the field

- Retaining the copyright to your article

Submit your next manuscript at springeropen.com 